\title{
A Voter-Centered, Voter-First Approach to Elections
}

\author{
Amber McReynolds
}

Abstract Identifying new and innovative approaches to enhance voter experience and process transparency is an important component of election administration. This case presents the professional experience of one election administrator and provides recommendations for election administrators, elected officials, and voters to ensure that our election systems are secure.

Keywords Data visualization $\bullet$ Communication $\bullet$ Voters $\bullet$ Elected officials • Election security

\section{Background-Why Denver Is Denver Today}

When I started at the elections office in Denver over 13 years ago, as an energetic and passionate 26-year-old, I was excited for the opportunity to serve. I quickly found a culture that devastated me. I asked questions and tried to learn and found very little to help me. I found very little

A. McReynolds ( $\square)$

National Vote at Home Institute, Denver, CO, USA

Denver Elections Division, Denver, CO, USA

e-mail: amber@voteathome.org

(C) The Author(s) 2019

M. Brown et al. (eds.), The Future of Election Administration, Elections, Voting, Technology, https://doi.org/10.1007/978-3-030-18541-1_21 
commitment to serving customers, an extraordinary disinterest in continuous improvement, and inefficiency across the board. The motto of the day was 'we have always done things this way and we will continue doing things this way.' I thought that maybe these responses were found only in this office, but I found this same sentiment almost everywhere I went in the election administration industry.

So, after many frustrating first days, I decided that I would learn as much as I could, build systems and processes (that did not exist) for the area that I was responsible for, and, some day, if I had a chance, I would lead change.

The turmoil in management and executive leadership continued. There were leaders in positions that were not qualified or had very little interest in serving the public. It was a difficult, trying, and disappointing place to work. Then, in 2006, as a result of these leadership issues, complete technology failure, and lack of planning, there was a bad election that impacted thousands of voters across the city. My little area for absentee ballots for the most part worked well but we were closed down by the technology failures that I and a few of us had tried to bring attention to before the election.

After that, Denver voters voted to change the governance structure and opted for an elected clerk and recorder instead of the commission that existed before. The first clerk and recorder started to meet with all the staff. At that time, I actually had a job offer to go to the State Elections Office. After all the turmoil at the Denver office, I thought it would be the right decision. Then I met with Clerk O'Malley, who to this day is a mentor and friend to me. I was nervous for my meeting but optimistic to make things better after a painful two years. We had a wonderful meeting and at the end, she said, do you want to be a part of the change here? I didn't hesitate at all and said yes. I was promoted to be a manager and started to make changes within the areas for which I had responsibility. We had new leadership and a sense of urgency. The organization needed to be restructured and we knew that had to happen first. Further, we desperately needed more resources. In the transition, more than half of the previous staff left and we started to hire new staff. After a few months, I applied for the Deputy Director position, but they hired someone that had come in second for the Director job. That was ok for me and I continued to do all that I could to improve the office. Things didn't go well with the Deputy. He was never there and frankly just gave me most of his work including hiring staff. I'll never forget the day, he came to my desk as he was leaving 
for a five-day weekend, and handed me a pile of probably 300 pages of resumes and applications that had been in his desk for over a month. He said, we need to hire an Administration Manager and I haven't had time to look at these, can you find someone. I started to look through the applications and found that they were more than two months old so I decided to stay that night and go through them so that I could invite them in for interviews. I read them and marked five to send emails to which I did promptly that night. One was for an applicant named Lisa.

I emailed Lisa and asked her for an interview. She responded quickly and said that she was surprised to receive the email since it had been four months since she applied, which for me flagged another inefficiency in the city's process for hiring! We interviewed Lisa (along with other applicants) and I hired her.

Today, Lisa is part of the senior management team and serving as Administration Deputy Director for the Denver Elections Office. To this day, she is a star, a dedicated public servant, and, behind the scenes, a vibrant part of the culture of the Denver Elections Office. Since that time, we have hired some of the most talented and committed individuals in this industry, many of whom I believe will be stars in the election world but more broadly in public service.

This story demonstrates the change that needed to happen. We had to change and we had to do it quickly, perhaps even too quickly. I never wanted to see voters go through a painful process to vote, wait in line, or experience deficient customer service. We had to create a culture that included values of service, commitment, excellence, and innovation. To attract the best, we had to offer a culture of excellence and be a top election office. So that's what we set out to do.

\section{Denver Elections Today}

I had the honor of serving the City and County of Denver, Colorado, as the Director of Elections for 7 years and administrator for over 13 years. Today, Denver is committed to ensuring that its citizens have an outstanding voting experience. The elections team is extraordinarily committed to serving voters and facilitating this fundamental democratic process. During my tenure in local government administration, I learned very quickly that all elections are essential-from presidential elections to local school board elections - and it is important for election officials and local government institutions to support voters throughout the process. 
As a dynamic, highly complex, and decentralized ecosystem, the election administration field involves commitment by federal, state, and local election officials but also technologists, stakeholders, advocacy groups, and above all-voters. Let me say that again. Voters are the key and making their experience meaningful, accessible, and secure is the ultimate goal. We as a community must continue to improve our service delivery to voters, respond to their needs, and facilitate a fair and accessible process. I believe this process must be free from partisan politics and must be centered around doing what's right for all voters, regardless of political persuasion.

Thus, to solve critical issues, including ensuring that our election systems are secure, I would offer the following as a call to action.

To election administrators - Support your voters, connect with them, and listen to them. You can do this specifically by collecting and analyzing customer service-related data. The winning formula is as follows: streamline the voting experience + advocate for voter-centric changes $=$ improve internal operations, gain efficiency, and improve service. Election administration is a local phenomenon and it is local election officials who deliver a direct service to voters. Federal and state officials provide support to the local election offices with rules and regulations that provide consistent practice, training, voter registration systems, and other secondary support.

Action steps for election officials:

1. Develop and cultivate a culture of commitment, excellence, service, creativity, curiosity, innovation, and learning. A great book that I believe is essential is 'What's Right, not Who's Right' by Robert Tipton ${ }^{1}$

2. Embrace process improvement strategies and techniques. Elections are about people and process. Streamlining the process and identifying waste will improve service delivery. Denver offers a training program to other jurisdictions. ${ }^{2}$

3. Tell the story - collect and analyze data to improve service delivery and enhance the voting experience. Share and publish your data and your successes. Measurement is key to continuous improvement. Show what you have accomplished, and why it matters. Figure 21.1 shows

${ }^{1}$ Robert Tipton, What's Right Not Who's Right: A Simple Shift to End the World's Madness (Denver, CO, Alden-Swain Press, 2018).

${ }^{2}$ www.DenverGov.org/PeakAcademy. 


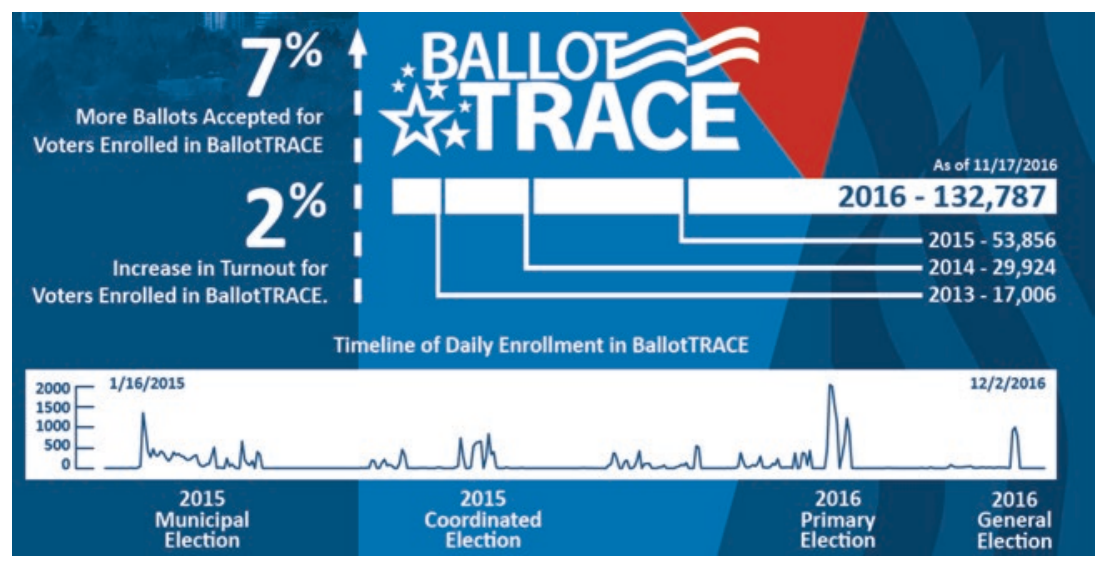

Fig. 21.1 Example of visualized data that summarizes the impact of process improvement at Denver Elections

some examples of the visual displays of data that we have used in the Denver office that summarize the impact of process improvement. ${ }^{3}$

4. Continue to improve. Conduct post-election debriefs and look for opportunities to improve. This step is extremely important to review and celebrate success while identifying opportunities for the future.

To elected officials - Listen to your local election administrators, respect voters, and give voters a chance. Once your election is over, you represent all voters, not just those who cast a vote for you or donated to your campaign. Regardless of your party affiliation, you should advocate for fair, accessible, secure, transparent, and efficient election processes. Barriers and burdens in the election process such as restrictive voter registration deadlines, overly prescriptive residency requirements, and lack of options to vote outside of a specific time are not productive for voters and not at all efficient in terms of the procurement and funding of voting systems, and thus are woefully unfair to taxpayers.

Colorado modernized its voting model in 2013 (HB13-13034) and now is a leading state in terms of policy innovation, election administration,

${ }^{3}$ From Denver Elections 2016 Summary Report Available at www.DenverVotes.org.

${ }^{4}$ Colorado House Bill 13-1303 Final Bill: http://www.colorado.gov/clics/clics2013a/ commsumm.nsf/b4a3962433b52fa787256e5f00670a71/8cecafdefa56797987257b57007 cbb54? OpenDocument. 
and civic engagement. At that time, there was opposition by some, but our coalition of election officials, many of the county clerks, and advocacy groups was able to advocate for and pass the most comprehensive election reform package in Colorado's history. Now, there is documented evidence $^{5}$ of the positive impact this reform has had to improve the voting experience, increase civic engagement, reduce costs, and above all-more effectively serve voters. ${ }^{6}$

To voters - Tell us what you want and set high expectations. You deserve a voting process that is efficient, accessible, secure, and reliable-one that respects you and your right to vote and to participate.

The Denver Elections Office listens to voters by analyzing the customer service data and then builds systems that provide the information proactively; as an example, Ballot TRACE was created as a result of voter calls (Fig. 21.2). ${ }^{7}$ Ballot TRACE is a first-in-the-nation Ballot Tracking Reporting and Communications Engine. It provides visibility and accountability for ballots that are mailed out to voters either automatically or by request. Ballot TRACE is an effective communication tool that provides customer service information to voters. Further, it is important to put voters' needs at the center of the decision-making process by analyzing data and metrics, utilizing creative design thinking, and continuing to look for opportunities to improve. ${ }^{8}$

\section{What is Ballot TRACE?}

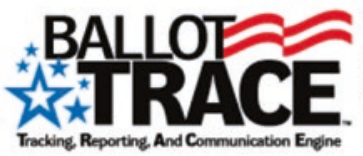

Ballot TRACE is an award-winning, innovative mail

ballot Tracking, Reporting, And Communication Engine developed for Denver's mail ballot voters by the Denver Elections Division.

Fig. 21.2 Ballot TRACE

\footnotetext{
${ }^{5}$ https://www.nonprofitvote.org/documents/2017/03/america-goes-polls-2016.pdf/.

${ }^{6}$ https://www.pewtrusts.org/ /media/assets/2016/03/coloradovotingreformsearlyresults.pdf.

${ }^{7}$ https://www.denvergov.org/pocketgov/\#/ballot/lookup.

${ }^{8}$ Visit www.DenverVotes.org for data visualizations and historical analysis.
} 


\section{CONCLUSION}

Election administration starts at the local level but is extremely complex and requires coordination with state and federal entities, especially with regard to security. Ensuring that our elections are fair, accurate, accessible, secure, and transparent requires commitment, collaboration, coordination, and communication across all levels of government. And it should be free from partisan politics, with a focus on who votes not who wins, and it is my sincere hope that a solution-orientated approach is the ultimate path forward. As election officials, we must do what's right for voters to make their experience meaningful. By focusing our election administration processes and problem-solving efforts on the voter, from start to finish in all our processes, we can develop solutions that accomplish that goal.

Open Access This chapter is licensed under the terms of the Creative Commons Attribution 4.0 International License (http://creativecommons.org/licenses/ by $/ 4.0 /)$, which permits use, sharing, adaptation, distribution and reproduction in any medium or format, as long as you give appropriate credit to the original author(s) and the source, provide a link to the Creative Commons licence and indicate if changes were made.

The images or other third party material in this chapter are included in the chapter's Creative Commons licence, unless indicated otherwise in a credit line to the material. If material is not included in the chapter's Creative Commons licence and your intended use is not permitted by statutory regulation or exceeds the permitted use, you will need to obtain permission directly from the copyright holder.

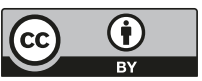

